DOI: $10.17805 /$ trudy.2019.4.4

\title{
ТРАДИЦИОННАЯ И КОМПЕТЕНТНОСТНАЯ ПАРАДИГМА В ОБРАЗОВАНИИ: ПРОСТО О СЛОЖНОМ
}

\author{
А. В. Артемьев \\ Московский гуманитарный университет
}

Аннотация: В статье определяется основное отличие компетентностной парадигмы от традиционной парадигмы образования.

Ключевые слова: традиционное образование; традиционная парадигма, компетентностная парадигма

\section{TRADITIONAL AND COMPETENCE-BASED PARADIGM IN EDUCATION: DIFFICULT MATTER IN SIMPLE WORDS}

\author{
A. V. Artemyev \\ Moscow University for the Humanities
}

Abstract: The article defines the main difference between the competence-based paradigm and the traditional paradigm in education.

Keywords: traditional education; traditional paradigm, competence-based paradigm

В ходе развития общества и перехода от традиционного к индустриальному, от индустриального к постиндустриальному обществу, изменялись установки и социально-обусловленные требования к образованию человека, выраженные как в личностной составляющей, так и профессиональной. В связи с этим в истории общества сложилось множество парадигм образования, определяющих цели и задачи образования на определенный исторический период общества.

Традиционно-консервативная (знаниевая) модель образования, положившая начало консерватизму в XVIII веке, ставит перед собой главную цель образования - знания, умения и навыки. Традиционная парадигма определяет задачи «сбережения» общечеловеческих ценностей и их передачу молодому поколению, подразумевающей под собой индивидуальное развитие обучающихся. Основной вопрос, который ставит перед собой традиционная модель образования, это «Чему учить?», то есть какие знания, умения и навыки передавать человеку в определенный исторический пери- 
од. Традиционно-консервативная (знаниевая) модель образования имела весьма положительные результаты в период индустриализации общества, и отвечала требованиям того исторического периода.

Начало XX века ознаменовано переходом к постиндустриальному обществу, новый исторический период предопределяет новые требования к образованию, что послужило возникновению новой парадигмы образования - компетентностной парадигмы.

Компетентностная парадигма образования, придя на смену традиционно-консервативной (знаниевой) парадигмы, изменяет и корректирует основную цель образования, где теперь это не знания, умения и навыки, а компетенции, отражающие собой формы и методы обучения. При компетентностной парадигме выраженной компетентностным подходом, формы и методы обучения не подбираются под содержание, а наоборот диктуют содержание образования, теперь вместо главного вопроса педагогики «Чему учить?», в условиях компетентностной модели образования, главный вопрос не чему учить, а «Как учить!»

Для того чтобы определить существенное различие традиционно-консервативной и компетентностной парадигмы образования, и самое главное определить тем самым их эффективность и влияние на человека в период постиндустриального общества, необходимо обратиться к сравнению двух ключевых образовательных парадигм XVIII века и начала XX в.

Понятие «компетенция» происходить от латинского слова competere, что в переводе означает - 'соответствовать', 'подходить' (Зимняя, 2003). Само по себе понятие «компетенция» в настоящее время все больше подвержено изучению рядом исследователей психолого-педагогического направления, а также активно исследуется социологией и экономикой. Интерес исследователей вызван, прежде всего, активным внедрением понятия «компетентность» в систему образования, в том числе как одну из категорий оценки результатов профессиональной деятельности специалиста, выраженное в его способностях, а именно: знаниях, умениях и навыках.

Возникновение понятия «компетентность» принято относить к исследованиям американского лингвиста Н. Хомского. Н. Хомский сформулировал понятие «компетентность» примирительно к теории языка, трансформационной грамматике. Н. Хомский утверждал « ... мы проводим фундаментальное различие между компетенцией (знанием своего языка говорящим - слушающим) и употреблением (реальным использованием языка в конкретных ситуациях). Только в идеализированном случае ... употребление является непосредственным отражением компетенции. В действительности же оно не может непосредственно отражать компетенцию ... противопоставление, вводимое мною, связано с соссюровским противопоставлением языка и речи, но необходимо ... скорее вернуться к гумбольдтовской концепции скрытой компетенции как системы порождающих процессов» (цит. по: Зимняя, 2003: 39). 
Научные труды Московского гуманитарного университета 2019 № 4

Исходя из исследования Н. Хомского, можно сделать вывод, что под «знанием языка», он понимал «компетентность», а под «употреблением языка» - его использование. В данном случае он разграничивает оба понятия, так как знание человеком языка, не всегда сопоставимо с тем, что человек говорит и как он это говорит, то есть он имеет ввиду что с одной стороны можно определить по употреблению языка человеком в диалоге о его компетенции, то есть как уже определили «знание» языка, но в тоже время употребление языка, не всегда может говорить о реальном знание языка, так как ситуация в которой находится участник коммуникативного акта, может повлиять на возможность в полной мере использовать свой язык, данный случай Н. Хомский описывает как «коммуникативная компетенция», то есть способность и возможности использования реальные знания языка в жизнедеятельности человека.

После введения понятия Н. Хомским «компетенция», оно активно начинает использоваться в различных отраслях научных знаний, не исключением являлось и система образования. В 1960-ые годы в Америке понятие «компетенция» начинает использоваться в педагогическом аспекте. Система американского образования начинает концентрироваться на компетенции в образовании (competence-based education - CBE) (Зимняя, 2009). Целью ориентации на компетенции являлась и является подготовка конкурентно способных специалистов на рынке труда. Сама по себе концепция предполагала своего рода, систему — «автоматизированных знаний», в результате которых, формировались практические навыки.

По мнению Т. А. Разуваевой, «такой подход подвергся резкой критике, суть которого, заключалась в том, что компетенции в виде практических знаний были недостаточны для развития творчества и индивидуальности учащихся» (Разуева, 2010: 268). В результате в 1970-х годах было предложено различать два понятия компетентность и компетенция (competency and competence) (там же). Компетентность стала, рассматривается как личностная категория, а компетенция как единица образовательной программы специалиста, что являлось предпосылкой для возникновения новой парадигмы в образовании - «компетентностной парадигмы в образовании».

И. А. Зимняя, основываясь на научных трудах А. В. Хуторского, определяет конец XX - начало XXI века как период характерных изменений в характере образования, ориентируя содержание образования, на свободное развитие человека, творческую инициативу, самостоятельность обучающихся (Зимняя, 2009: 7), все это находит свое отражение в направление принятом государством нормативно-правового регулирования системы образования, и в первую очередь в «Концепции модернизации образования до 2010 года», обращаясь к которой, мы можем видеть смену образовательной парадигмы. Зимняя отмечает, что традиционная парадигма образования, включающая в себя концепцию «ЗУН» - или по-другому, парадигма результата образования», включающая в себя теоритические основания, 
иерархию знаний, умений и навыков, а самое главное методик их освоения. Традиционная парадигма принималась педагогическим сообществом и до сих пор принимается некоторой ее частью (Зимняя, 2009: 8).

В условиях происходящих как в мире, так и в России изменений в области корректировок целей образования, которые должны соотносится в частности, с глобальной задачей образования, обеспечения вхождения человека в социальный мир, его продуктивной адаптацией в этом мире, как отмечаем И. А. Зимняя, все это вызывает необходимость постановки вопроса обеспечения образованием более полного, личностного и социально интегрированного результата, где в качестве общего определения такого интегрального социально-личностно-поведенческого феномена как результата образования в совокупности мотивационно-ценностных, когнитивных составляющих и выступило понятие «компетенция/компетентность» (там же). В результате на сегодняшний день, мы наблюдаем формирование новой парадигмы образования - компетентностной парадигмы образования.

И. А. Зимняя производит анализ зарубежной литературы по данной проблематике и предлагает понимать под компетенцией некоторые внутренние, потенциальные, сокрытые психологические новообразования (знания, представления, программы (алгоритмы) действий, системы ценностей и отношений), которые затем выявляются в компетентностях человека как актуальных, деятельностных проявлениях (Зимняя, 2009). Компетентность, в свою очередь, следует понимать как комплексный личностный ресурс, обеспечивающий возможность эффективного взаимодействия с окружающим миром в той или иной области и зависящий от необходимых для этого компетенций, компетентность всегда есть актуальное проявление соответствующих компетенций (Зимняя, 2003: 31).

Г. А. Рагозина, исследуя перспективное будущее компетностной парадигмы и сравнивания ее с традиционной парадигмой, утверждает, что традиционная парадигма образования в свете технологического прогресса, не отвечает сегодняшним требованиям, предъявляемым к качеству Российского образования, обосновывая это тем, что ключевой ценностью традиционной парадигмы выступают знания, и если в период с XVIII века по начало XXI века, знания действительно имели уникальное, достоверное свойство, то сегодня их достоверность может быть преувеличена, если в условиях СССР знания имели высшую ценность для общества и их поток и передача контролировались, то сегодня в условиях современности, знания в «чистом виде» теряют свою ценность. Сегодня в условиях эры «цифрового человека» уже недостаточно систематически передавать накопленные знания, при этом компетентностная модель определяет одно из ключевых мест для передачи знаний. Как утверждает Г. А. Рагозина, сегодня, если осваивать только знания, то человек не получит «социального движения», личностное и профессиональное развитие будет регрессировать в условиях постиндустриального общества (Рагозина, 2014). Знаниевая модель обра- 
зования (она же традиционная), несет в себе формально-логический принцип обучения, формируя в человеке заранее запрограммированные знания.

Основное отличие компетентностной парадигмы образования является ее преимущество, выраженное в объединение основных концепций парадигм образования разного исторического периода в одно. Так традиционно-консервативная (знаниевая), личностная и культурологическая, объединившие в себе все самые значимые принципы, образовали компетентностную парадигму образования, которая способствует становлению компетентного специалиста, определяя его личностное и профессиональное развитие, нравственные ценности и роль в обществе, тем самым отвечая требованиям современного общества к будущим специалистам.

\section{СПИСОК ЛИТЕРАТУРЫ}

Зимняя, И. А. (2003) Ключевые компетенции - новая парадигма результата образования // Высшее образование сегодня. № 5. С. 34-42.

Зимняя, И. А. (2009) Ключевые компетенции - новая парадигма результата образования// Эксперимент и инновации в школе. № 2. С. 7-13.

Разуваева, Т. А. (2010) Компетентностный подход к образованию: краткий теоретический анализ // Вестник КГУ им. Некрасова. № 1. С. 266-269.

Рагозина, Г. А. (2014) Значение компетентностной парадигмы в образовании // Поволжский научный вестник. № 2 (30). С. 159-166.

Дата поступления: 15.08.2019 г.

Артемьев Алексей Васильевич - магистрант кафедры педагогики и психологии высшей школы Московского гуманитарного университета. Адрес: 111395, Россия, г. Москва, ул. Юности, д. 5 . Тел.: +7 (499) 374-74-59. Эл. адрес: artemev0296@mail.ru. Научный руководитель - д-р пед. н., проф. В. А. Ситаров.

Artemyev Aleksey Vasilyevich, Graduate Student, Department of Pedagogy and Psychology of Higher Education, Moscow University for the Humanities. Postal address: 5, Yunosti St., Moscow, Russian Federation, 111395. Tel.: +7 (499) 37474-59. E-mail: artemev0296@mail.ru. Scientific Adviser - V. A. Sitarov, Doctor of Pedagogy, Professor.

\section{Для цитирования:}

Артемьев А. В. Традиционная и компетентностная парадигма в образовании: просто о сложном [Электронный ресурс] // Научные труды Московского гуманитарного университета. 2019. № 4. URL: http://journals.mosgu.ru/trudy/article/view/1012 (дата обращения: дд.мм.гг.). DOI: 10.17805/trudy.2019.4.4 